\title{
Hereditary isolated aplastic anemia
}

INSERM

\section{Source}

INSERM. (1999). Orphanet: an online rare disease and orphan drug data base. Hereditary isolated aplastic anemia. ORPHA:397692

Hereditary isolated aplastic anemia is a rare, genetic, constitutional aplastic anemia disorder characterized by severe peripheral blood pancytopenia and bone marrow hypoplasia in multiple individuals of a family, in the absence of any somatic symptoms. Abnormal bleeding, as well as erythrocyte macrocytosis, is reported and patients usually become transfusion-dependent. 